\title{
Allicin attenuates $\mathrm{H}_{2} \mathrm{O}_{2}$-induced cytotoxicity in retinal pigmented epithelial cells by regulating the levels of reactive oxygen species
}

\author{
GERILE TU ${ }^{1}$, YU-FENG ZHANG ${ }^{1}$, WEI WEI ${ }^{2}$, LANGEN LI $^{1}$, YANMEI ZHANG ${ }^{3}$, JIA YANG ${ }^{4}$ and YIQIAO XING ${ }^{1}$ \\ ${ }^{1}$ Department of Ophthalmology, Renmin Hospital of Wuhan University, Wuhan, Hubei 430060; \\ Departments of ${ }^{2}$ Ophthalmology and ${ }^{3}$ Neurology, Inner Mongolia People's Hospital, Hohhot, Inner Mongolia 010017; \\ ${ }^{4}$ Department of Ophthalmology, First Affiliated Hospital of Inner Mongolia Medical University, \\ Hohhot, Inner Mongolia 010059, P.R. China
}

Received February 2, 2015; Accepted December 10, 2015

DOI: $10.3892 / \mathrm{mmr} .2016 .4797$

\begin{abstract}
Retinal pigmented epithelial cell (RPE) oxidative stress is known to have a vital role in the etiology of age-related macular degeneration (AMD). The present study aimed to investigate whether allicin, a natural product with antioxidant activity, was able to protect RPEs (ARPE-19) from hydrogen peroxide $\left(\mathrm{H}_{2} \mathrm{O}_{2}\right)$-induced damage, and to determine the underlying mechanisms. The 3-(4,5-dimethylthiazol-2-yl)-2,5-diphenyl tetrazolium bromide assay was used to determine cellular viability, and reactive oxygen species (ROS) were detected using a ROS Assay kit. The results demonstrated that allicin was able to protect ARPE-19 cells from $\mathrm{H}_{2} \mathrm{O}_{2}$-induced damage in a dose-dependent manner. In addition, allicin attenuated oxidative stress by reducing the levels of intracellular ROS and malondialdehyde (MDA), and enhancing the glutathione/glutathione disulfide (GSSG) ratio. With regards to the underlying mechanism, allicin was able to markedly modulate the expression levels of ROS-associated enzymes, including superoxide dismutase, NADPH oxidase 4 and $\mathrm{NAD}(\mathrm{P}) \mathrm{H}$ dehydrogenase quinone 1 , and elevate the activity of nuclear factor erythroid 2-related factor 2 in the $\mathrm{H}_{2} \mathrm{O}_{2}$-stimulated ARPE-19 cells. These results suggested that allicin may exert protective effects against $\mathrm{H}_{2} \mathrm{O}_{2}$-induced cytotoxicity in RPEs via ROS regulation.
\end{abstract}

\section{Introduction}

Retinal pigmented epithelial cells (RPEs) comprise a single layer of epithelial cells, which is located between the light-sensing photoreceptor cells and the choriocapillaris (1). RPEs, which are highly metabolically active, are sensitive to

Correspondence to: Dr Yiqiao Xing, Department of Ophthalmology, Renmin Hospital of Wuhan University, 99 Zhang Zhidong Road, Wuchang, Wuhan, Hubei 430060, P.R. China E-mail: yqxingwh@sohu.com

Key words: garlic, retinal pigmented epithelial cells, age-related macular degeneration, oxidative stress oxidative stress when retinal cells are exposed to high levels of reactive oxygen species (ROS) (2). Abnormal RPEs are regarded as an important contributor to age-related macular degeneration (AMD), a disease that results in irreversible visual blindness in the elderly population $(3,4)$. Although the pathogenic mechanism underlying the progression of AMD is currently unknown, previous studies have suggested that the pathogenesis of AMD is associated with oxidative stress-induced cumulative damage to RPEs, which occurs in response to excessive production of ROS or abnormal ROS homeostasis $(5,6)$. Therefore, the identification of strategies that protect RPEs from oxidative stress-induced damage, thus preventing or delaying the progression of AMD, is required.

Consumer preference for natural products and functional foods, which are considered to be largely harmless, has recently been increasing (7). With regards to targeting AMD, novel drugs with antioxidant and natural properties have garnered much attention. The present study focused on allicin, which is a defense molecule present in garlic (8). Allicin is a component of garlic that exerts several biological activities. It has previously been reported that allicin exerts antimicrobial, immune-modulatory and anticancer activity (9). Furthermore, allicin exerts antioxidant effects at the physiological level when administered at lower doses (9). The well-known protective effects of allicin against oxidative stress have been shown to target cardiovascular diseases, which are frequently correlated with oxidative stress $(10,11)$. In addition, allicin exerts cardioprotective effects via activation of redox-sensitive transcription factors, including nuclear factor erythroid 2-related factor 2 (Nrf2) (12). Allicin has also been demonstrated to exert beneficial cardiovascular effects by preventing cardiac hypertrophy, hyperlipidemia and platelet aggregation (13). In vivo, allicin has been shown to attenuate fatty streaks, which are associated with atherosclerosis, in mice fed a high fatty acid diet (14). Allicin not only protects against cardiovascular diseases, but also protects against various other age-related diseases, including neurodegenerative diseases with age-related cognitive and memory deficits. Li et al (15) demonstrated that allicin markedly improved ageing-induced cognitive dysfunction via the activation of Nrf2 signaling pathways. Therefore, allicin may be considered a potential candidate for the treatment of cognitive deficits in aging and Alzheimer's disease (15). The present study hypothesized that allicin may 
counteract other age-related diseases, such as AMD, due to its high antioxidant effect and potential as a therapy for the treatment of cardiovascular diseases and Alzheimer's disease.

The aim of the present study was to explore whether allicin could protect ARPE-19 cells from hydrogen peroxide $\left(\mathrm{H}_{2} \mathrm{O}_{2}\right)$-induced damage, and to determine the molecular mechanism underlying the effects of allicin on $\mathrm{H}_{2} \mathrm{O}_{2}$-stimulated ARPE-19 cells. Briefly, $\mathrm{H}_{2} \mathrm{O}_{2}$ was used to stimulate ARPE-19 cells, and to establish a cellular model of AMD. Subsequently, the effects of allicin on $\mathrm{H}_{2} \mathrm{O}_{2}$-stimulated ARPE-19 cells were detected, and further studies were performed to determine which biological effects of allicin were dominant in the $\mathrm{H}_{2} \mathrm{O}_{2}$-stimulated ARPE-19 cells.

\section{Materials and methods}

Cell culture. The ARPE-19 human RPE cell line was purchased from the American Type Culture Collection (Manassas, VA, USA). The cells were cultured in Dulbecco's modified Eagle medium (DMEM) supplemented with $10 \%$ heat-inactivated fetal bovine serum (FBS) (Gibco; Thermo Fisher Scientific, Inc., Waltham, MA, USA), $100 \mu \mathrm{g} / \mathrm{ml}$ streptomycin and $100 \mathrm{U} / \mathrm{ml}$ penicillin (CSPC Pharmaceutical Group Ltd., Shijiazhuang, China) at $37^{\circ} \mathrm{C}$ in an atmosphere containing $5 \% \mathrm{CO}_{2}$. The cells were passaged every 3 days once grown to $\sim 90 \%$ confluence.

Measurement of cell viability. ARPE-19 cells were grown to $80 \%$ confluence, and were treated with $\mathrm{H}_{2} \mathrm{O}_{2}(250$ or $500 \mu \mathrm{M}$; Sigma-Aldrich, St. Louis, MO, USA) for 12 or $24 \mathrm{~h}$ following supplementation with allicin $(5,10,20$ or $40 \mu \mathrm{g} / \mathrm{ml}$; $98 \%$ purity; Shaanxi Ciyuan Biotech Co., Ltd., Xian, China) for 4 h. Cells were harvested after the appropriate treatments. Cell viability was measured using a 3-(4,5-dimethylthiazol-2-yl)-2,5-diphenyl tetrazolium bromide (MTT) assay (Sigma-Aldrich). Briefly the cells were incubated with $50 \mu \mathrm{l}$ MTT at $37^{\circ} \mathrm{C}$ for $4 \mathrm{~h}$. Subsequently, the MTT-containing medium was discarded and $200 \mu \mathrm{l}$ dimethyl sulfoxide was added to the cells, in order to dissolve the formazan crystals. Optical densities (OD) were measured at $450 \mathrm{~nm}$ using a VersaMax microplate reader (Molecular Devices, Sunnyvale, CA, USA). Viability was calculated as OD value/cell number; untreated ARPE-19 cells (control group) were denoted as $100 \%$ viable.

Measurement of oxidative stress. An Intracellular ROS Assay kit (Cell Biolabs, Inc., San Diego, CA) was used to detect the intracellular ROS levels. Briefly, $100 \mu 1$ 2',7'-dichlorodihydro fluorescein diacetate (DCFH-DA) was added to the culture media of the ARPE- 19 cells for $30 \mathrm{~min}$ at $37^{\circ} \mathrm{C}$. Subsequently, the cells were washed twice with phosphate-buffered saline (PBS). DCFH fluorescence of the cell lysate was measured at an excitation wavelength of $485 \mathrm{~nm}$ and an emission wavelength of $535 \mathrm{~nm}$ using a FLUOstar optima (BMG LABTECH, Inc., Cary, NC, USA), and was quantified using ImageJ version 1.41 software (National Institutes of Health, Bethesda, MD, USA). The average fluorescence intensity was analyzed from five fields for each treatment. The relative fluorescence intensity was expressed as a percentage increase with reference to the intensity of the normal control cells. The glutathione (GSH)/glutathione disulfide (GSSG) ratio and malondialdehyde (MDA) concentrations were assessed using the GSH/GSSG Assay kit (Beyotime Institute of Biotechnology, Nantong, China) and the MDA Assay kit (Nanjing Jiancheng Biological Engineering Institute, Nanjing, China), according to the manufacturer's protocols. The superoxide dismutase (SOD) activity was measured using the SOD Assay kit (Nanjing Jiancheng Biological Engineering Institute), according to the manufacturer's protocols (16).

$R N A$ extraction and reverse transcription-quantitative polymerase chain reaction ( $R T-q P C R)$. Total RNA was extracted from the ARPE-19 cells using the RNeasy kit (Qiagen, Inc., Valencia, CA), and first-strand cDNA was synthesized using reverse transcription (RT) reagents (Takara Bio, Inc., Otsu, Japan) and SuperScript III (Invitrogen; Thermo Fisher Scientific, Inc.). RT was conducted in a total volume of $10 \mu \mathrm{l}$ containing $1 \mu \mathrm{l}$ RNA, which had been treated with $1 \mu \mathrm{l}$ RNase inhibitor (Promega Corporation, Madison, WI, USA). RT-qPCR was performed using an Applied Biosystems 7500 system (Applied Biosystems; Thermo Fisher Scientific, Inc.) and SYBR Premix Ex Taq kit (Takara Bio, Inc.). The PCR cycling conditions were as follows: $95^{\circ} \mathrm{C}$ for $10 \mathrm{~min}$, followed by 45 cycles at $95^{\circ} \mathrm{C}$ for $10 \mathrm{sec}, 57^{\circ} \mathrm{C}$ for $30 \mathrm{sec}$ and extension at $75^{\circ} \mathrm{C}$ for $10 \mathrm{sec}$, and a final $5 \mathrm{~min}$ extension step. The primer sequences used were as follows: NADPH oxidase 4 (NOX4), forward tatccagtccttccgttggtt, reverse ctgaggtacagctggatg ttga; Nrf2, forward gagaagtaccaggaggcgttg, reverse gagcct tggacaccaacagat; glyceraldehyde 3-phosphate dehydrogenase (GAPDH), forward ggagtcaacggatttggtc and reverse ggaatcatt ggaacatgtaaac (Sangon Biotech Co., Ltd., Shanghai, China). GAPDH was used as an internal control. Data were analyzed using the $2^{-\triangle \Delta C q}$ method of relative quantification (17).

Western blotting. The ARPE-19 cells were harvested at times appropriate to the indicated treatments. The cells were washed twice with PBS and were then lysed in order to extract the proteins. The nuclear proteins were extracted as previously described (18). Subsequently, the protein samples were isolated using a Protein Extraction kit (Qiagen $\mathrm{GmbH}$, Hilden, Germany) and were quantified with a Bio-Rad Protein Assay (Bio-Rad Laboratories, Inc., Hercules, CA, USA). The protein samples $(30 \mu \mathrm{g})$ were then separated by $10 \%$ sodium dodecyl sulfate-polyacrylamide gel electrophoresis and were transferred to nitrocellulose membranes (EMD Millipore, Bedford, MA, USA). The membranes were blocked for non-specific binding using $2 \%$ bovine serum albumin (Sigma-Aldrich) at $4^{\circ} \mathrm{C}$ overnight. Subsequently, the membranes were incubated with primary antibodies at $4^{\circ} \mathrm{C}$ overnight, and appropriate horseradish-peroxidase-conjugated secondary antibodies at room temperature for $1 \mathrm{~h}$ (1:500; cat. no. MA1-10371; Thermo Fisher Scientific, Inc.) . Signals were acquired using the Enhanced Chemiluminescence Detection system (SuperSignal West Femto; Pierce; Thermo Fisher Scientific, Inc.). Western blotting images from three independent experiments were scanned and quantified using Image J version 1.41 software (National Institutes of Health). Band intensities were assessed and normalized to the $\beta$-actin bands or Lamin B bands as indicated. The specific primary antibodies used were as follows: Anti-NOX4 (1:400; cat. no. HPA015475; Sigma-Aldrich), anti-NAD(P)H 

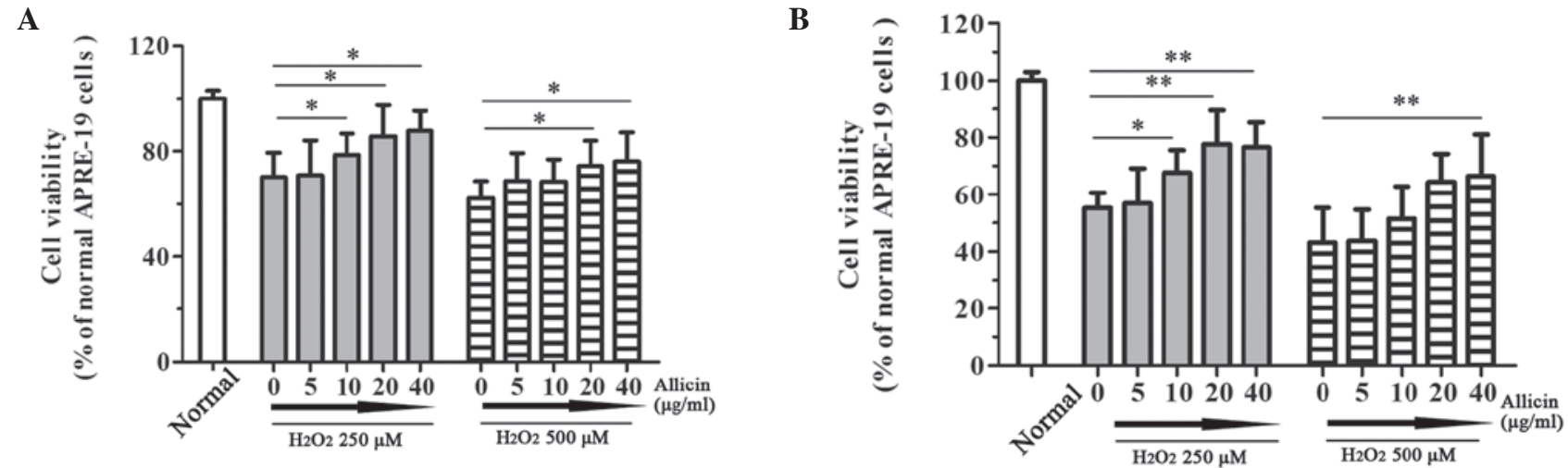

Figure 1. Allicin reduced the loss of viability induced by hydrogen peroxide $\left(\mathrm{H}_{2} \mathrm{O}_{2}\right)$ in ARPE-19 retinal pigmented epithelial cells. ARPE-19 cells were preincubated with various doses of allicin $(0,5,10,20$ or $40 \mu \mathrm{g} / \mathrm{ml})$ for $4 \mathrm{~h}$. Subsequently, the cells were exposed to $\mathrm{H}_{2} \mathrm{O}_{2}$ at 250 or $500 \mu \mathrm{M} \mathrm{for} \mathrm{(A)} 12 \mathrm{~h}$ and (B) $24 \mathrm{~h}$. Cell viability was measured using a 3-(4,5-dimethylthiazol-2-yl)-2,5-diphenyl tetrazolium bromide assay. Viability was calculated as optical density value/cell number; untreated control ARPE-19 cells (Normal) were denoted as 100\%. Data are presented as the mean \pm standard error of the mean. All experiments were performed in triplicate. Analysis of variance was performed to statistically analyze the data. ${ }^{*} \mathrm{P}<0.05$ and ${ }^{* *} \mathrm{P}<0.01$.

dehydrogenase quinone 1 (NQO1) (1:300; cat. no. N5288; Sigma-Aldrich), anti-Nrf2 (1:500; cat. no. 12721; Cell Signaling Technology, Inc., Danvers, MA, USA), anti- $\beta$-actin (1:1,000; cat. no. AV40173, Sigma-Aldrich) and anti-Lamin B (1:400; cat. no. SAB1306342; Sigma-Aldrich) antibodies.

Nrf 2 interference. The ARPE-19 cells were cultured in 96-well plates at a density of $2 \times 10^{4}$ cells/well. Non-targeting small interfering (si)RNA (final concentration $50 \mathrm{nM}$; Ambion; Thermo Fisher Scientific, Inc.) was used as a negative control. Human Nrf2 gene was silenced using Nrf2-specific siRNA (final concentration $30 \mathrm{nM}$ ) (Ambion; Thermo Fisher Scientific, Inc.). The cells were transfected using siPORT Amine transfection reagent (Ambion; Thermo Fisher Scientific, Inc.), according to the manufacturer's protocol (19). Following transfection for 12 or $24 \mathrm{~h}$, the expression levels of Nrf2 were determined by western blotting.

Statistical analysis. Data are presented as the mean \pm standard error of the mean. Student's t-test was used to analyze differences between two groups. The experimental results were analyzed using one-way analysis of variance to compare the differences between three or more groups. Statistical analyses were conducted using SPSS 17.0 software (SPSS, Inc., Chicago, IL, USA). All the experiments were performed at least in triplicate. $\mathrm{P}<0.05$ was considered to indicate a statistically significant difference.

\section{Results}

Allicin protects RPEs from $\mathrm{H}_{2} \mathrm{O}_{2}$-induced damage. In order to characterize the effects of allicin on $\mathrm{H}_{2} \mathrm{O}_{2}$-induced damage in RPEs, the cells were exposed to 250 or $500 \mu \mathrm{M} \mathrm{H}_{2} \mathrm{O}_{2}$ for 12 or $24 \mathrm{~h}$, following preincubation with various doses of allicin $(0,5,10,20$ or $40 \mu \mathrm{g} / \mathrm{ml})$ for $4 \mathrm{~h}$. Viability of the RPEs was assessed using an MTT assay. Treatment with $\mathrm{H}_{2} \mathrm{O}_{2}$ resulted in a significant loss of cell viability after 12 or $24 \mathrm{~h}$ exposure (Fig. 1). Notably, treatment with allicin reversed the effects of $\mathrm{H}_{2} \mathrm{O}_{2}$ on RPEs. As shown in Fig. 1A, the effects of allicin at various concentrations $(5,10,20$ or $40 \mu \mathrm{g} / \mathrm{ml})$ were determined following
A

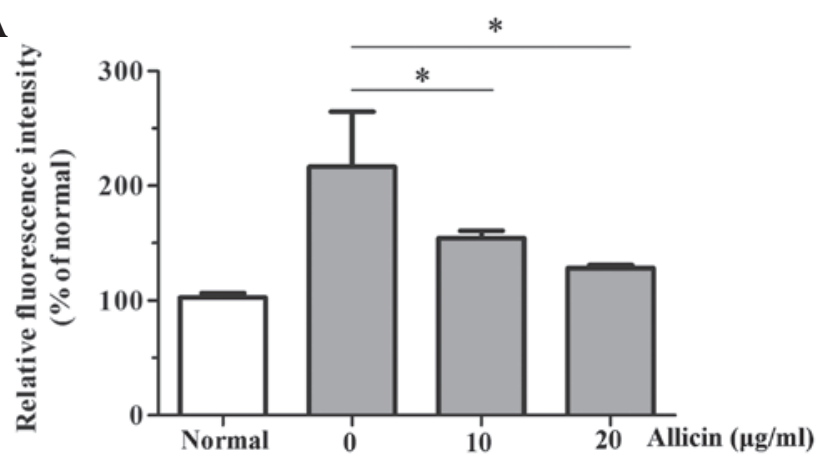

B

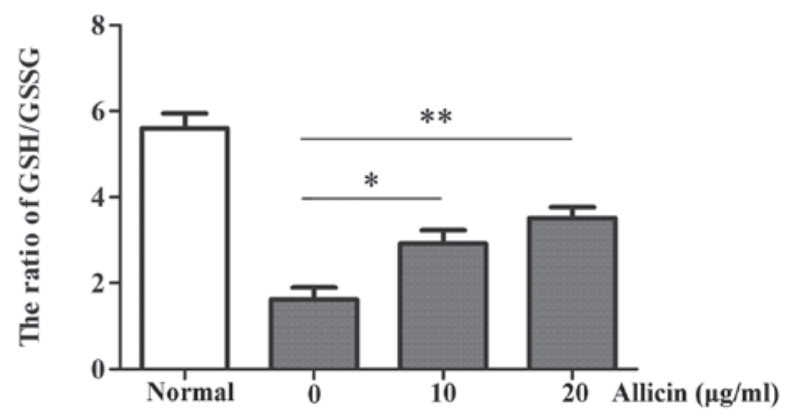

C

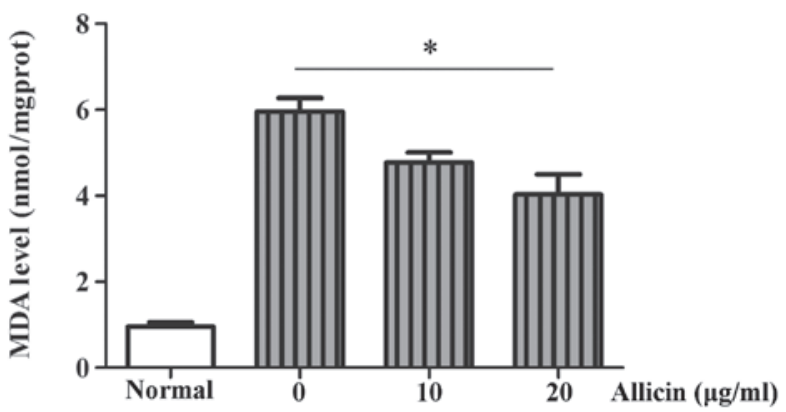

Figure 2. Allicin decreased hydrogen peroxide $\left(\mathrm{H}_{2} \mathrm{O}_{2}\right)$-induced oxidative stress in retinal pigmented epithelial cells (RPEs). Effects of allicin on (A) the levels of intracellular reactive oxygen species, (B) the glutathione (GSH)/glutathione disulfide (GSSG) ratio and (C) the levels of malondialdehyde (MDA) following $\mathrm{H}_{2} \mathrm{O}_{2}$ stimulation $(250 \mu \mathrm{M})$ of ARPE-19 cells Data are presented as the mean \pm standard error of the mean, $n=4$. Analysis of variance was performed to statistically analyze the data. ${ }^{*} \mathrm{P}<0.05$ and ${ }^{* * *} \mathrm{P}<0.01$ 

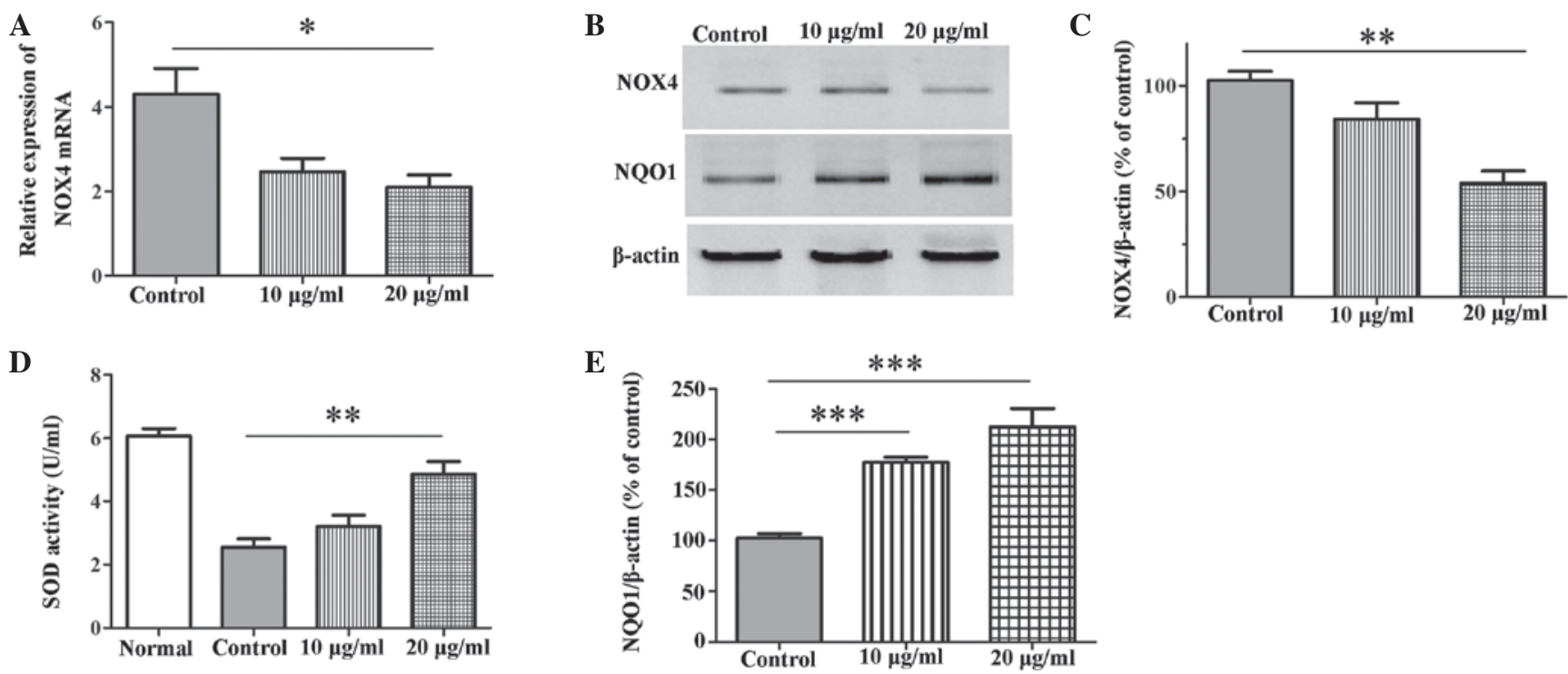

Figure 3. Effects of allicin on reactive oxygen species-associated enzymes in ARPE-19 retinal pigmented epithelial cells following treatment with hydrogen peroxide $\left(\mathrm{H}_{2} \mathrm{O}_{2}\right)$. (A) Relative mRNA expression levels of NADPH oxidase 4 (NOX4) were measured by reverse transcription-quantitative polymerase chain reaction. (B) Protein expression levels of NOX4 and NAD(P)H dehydrogenase quinone 1 (NQO1) were detected by western blotting. (C) Band intensities of NOX4 protein were assessed and normalized to $\beta$-actin bands. The NOX4 protein expression levels of ARPE-19 cells treated with $\mathrm{H}_{2} \mathrm{O}_{2}$ (control group) were denoted as $100 \%$. All experiments were performed in triplicate. (D) Activity of superoxide dismutase (SOD) was measured using a SOD assay kit, $\mathrm{n}=4$. (E) Band intensities of NQO1 protein were assessed and normalized to $\beta$-actin bands. Normal group, untreated cells; control group, cells treated with $250 \mu \mathrm{M}$ $\mathrm{H}_{2} \mathrm{O}_{2}$. Data are presented as the mean \pm standard error of the mean. ${ }^{*} \mathrm{P}<0.05,{ }^{* *} \mathrm{P}<0.01$ and ${ }^{* * *} \mathrm{P}<0.001$.

$12 \mathrm{~h} 250 \mu \mathrm{M} \mathrm{H}_{2} \mathrm{O}_{2}$-induced loss of viability. The percentage of viable cells was increased in response to $10-40 \mu \mathrm{g} / \mathrm{ml}$ allicin in a dose-dependent manner $(\mathrm{P}<0.05)$. These results suggest that allicin may suppress the loss of cell viability induced by $250 \mu \mathrm{M}$ $\mathrm{H}_{2} \mathrm{O}_{2}$. Furthermore, allicin exerted a significant protective effect against $12 \mathrm{~h} 500 \mu \mathrm{M} \mathrm{H}_{2} \mathrm{O}_{2}$-induced damage when administered at a concentration of $20 \mu \mathrm{g} / \mathrm{ml}(\mathrm{P}=0.039)$ or $40 \mu \mathrm{g} / \mathrm{ml}$ $(\mathrm{P}=0.032)$ (Fig. 1A). Following treatment with $250 \mu \mathrm{M} \mathrm{H}_{2} \mathrm{O}_{2}$ for $24 \mathrm{~h}$, allicin significantly attenuated the damaging effects on RPEs when administered at $10 \mu \mathrm{g} / \mathrm{ml}(\mathrm{P}=0.040), 20 \mu \mathrm{g} / \mathrm{ml}$ $(\mathrm{P}=0.008)$ or $40 \mu \mathrm{g} / \mathrm{ml}(\mathrm{P}=0.004)$. However, the protective effect of allicin reached a plateau when the concentration of allicin was increased to $20 \mu \mathrm{g} / \mathrm{ml}$ (Fig. 1B). In addition, allicin exerted protective effects against $24 \mathrm{~h} 500 \mu \mathrm{M} \mathrm{H}_{2} \mathrm{O}_{2}$-induced damage. These results suggest that allicin may protect RPEs from $\mathrm{H}_{2} \mathrm{O}_{2}$-induced damage.

Allicin reduces $\mathrm{H}_{2} \mathrm{O}_{2}$-induced oxidative stress in RPEs. Oxidative stress is characterized by a pathological state of excessive ROS production or abnormal ROS homeostasis $(6,20)$. The present study detected a protective role for allicin with regards to combating $\mathrm{H}_{2} \mathrm{O}_{2}$ stimulation in RPEs. Therefore, the present study aimed to determine whether allicin suppressed the $\mathrm{H}_{2} \mathrm{O}_{2}$-induced loss of cell viability by targeting ROS. The effects of allicin on intracellular ROS levels in RPEs were determined using the DCFH-DA assay. Allicin (10 and $20 \mu \mathrm{g} / \mathrm{ml})$ markedly reduced intracellular ROS levels $(\mathrm{P}=0.047$ and $\mathrm{P}=0.033)$, as compared with in the cells not treated with allicin (Fig. 2A). The GSH/GSSG ratio reflects the extent of oxidative stress in cells (21). In the present study, RPEs preincubated with allicin $(10 \mu \mathrm{g} / \mathrm{ml}, \mathrm{P}=0.037 ; 20 \mu \mathrm{g} / \mathrm{ml}, \mathrm{P}=0.007)$ were better at combating $\mathrm{H}_{2} \mathrm{O}_{2}$ injury, as compared with cells in the $\mathrm{H}_{2} \mathrm{O}_{2}$ group (Fig. 2B). MDA levels are considered a biomarker of oxidative stress (22).
The present study measured MDA levels in the ARPE-19 cells following $\mathrm{H}_{2} \mathrm{O}_{2}$ stimulation and allicin preincubation $(0$, 10 and $20 \mu \mathrm{g} / \mathrm{ml}$ ). Treatment with $\mathrm{H}_{2} \mathrm{O}_{2}$ resulted in a significant increase in MDA levels, which was downregulated following allicin preincubation in a dose dependent manner, especially when administered at $20 \mu \mathrm{g} / \mathrm{ml}(\mathrm{P}=0.027)$ (Fig. 2C).

Allicin-mediated protection of RPEs is associated with regulation of ROS-associated enzymes, SOD, NOX4 and NQO1. The present study detected the expression levels of NOX4, which is the key enzyme of the ROS generation system $(23,24)$, SOD, which is an important biomarker of oxidative stress (25), and NQO1, which is an important antioxidant enzyme (26). Treatment with allicin $(20 \mu \mathrm{g} / \mathrm{ml})$ significantly downregulated the mRNA and protein expression levels of NOX4 (mRNA, $\mathrm{P}=0.031$; protein, $\mathrm{P}=0.003$ ) following exposure of the cells to $250 \mu \mathrm{M} \mathrm{H}_{2} \mathrm{O}_{2}$ for $24 \mathrm{~h}$ (Fig. 3A-C). $\mathrm{H}_{2} \mathrm{O}_{2}$ significantly inhibited the levels of SOD, and pretreatment with allicin significantly attenuated this inhibition when administered at a concentration of $20 \mu \mathrm{g} / \mathrm{ml}$ ( $\mathrm{P}=0.009$; Fig. 3D). In addition, allicin was able to markedly increase the protein expression levels of NQO1 when administered at a concentration of $10 \mu \mathrm{g} / \mathrm{ml}$ or $20 \mu \mathrm{g} / \mathrm{ml}$ $(\mathrm{P}<0.001$; Fig. 3B and $\mathrm{E})$.

Effects of $N r f 2$ regulation on allicin-mediated protection against $\mathrm{H}_{2} \mathrm{O}_{2}$-induced injury. To further understand the protective effects of allicin against $\mathrm{H}_{2} \mathrm{O}_{2}$-induced damage, the expression levels of $\mathrm{Nrf} 2$, which has an essential role eliminating oxidants by reinforcing cellular antioxidant capacity, were detected (27). As shown in Fig. 4A, the relative mRNA expression levels of Nrf2 were enhanced by allicin in a dose-dependent manner $(\mathrm{P}<0.05)$, as compared with the $\mathrm{H}_{2} \mathrm{O}_{2}$-treated control cells. Furthermore, the cytosolic and nuclear protein expression levels 


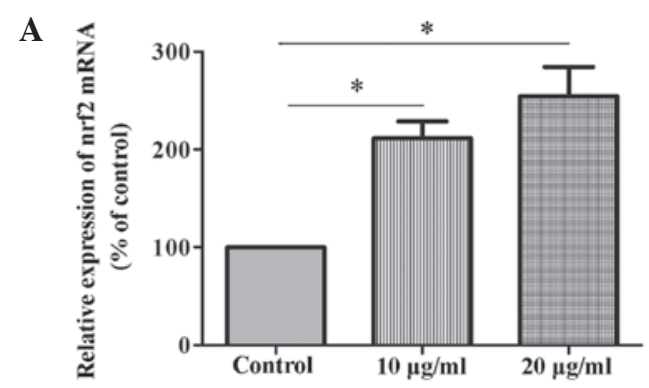

B

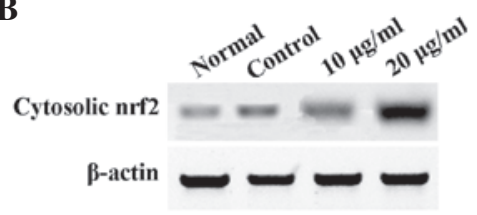

D
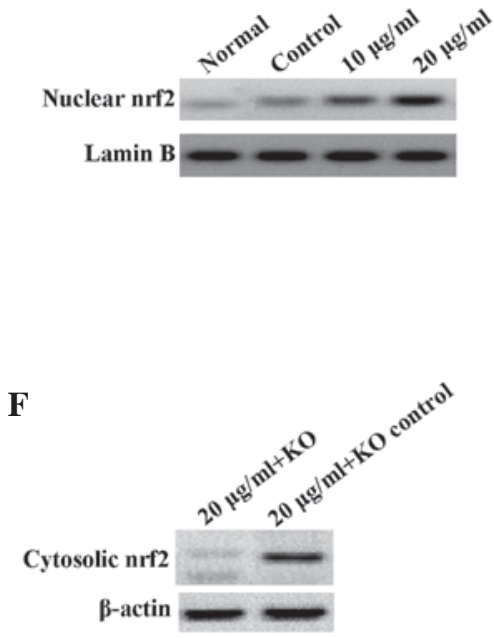

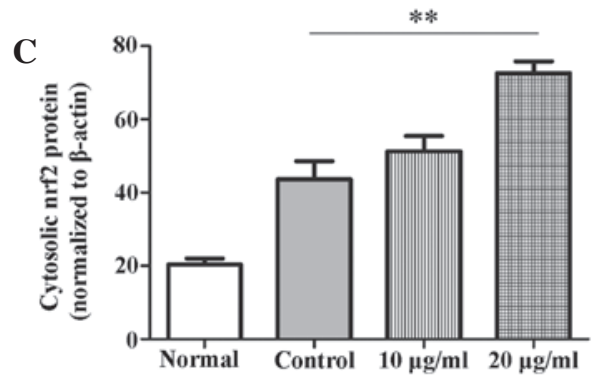

$\mathbf{E}$
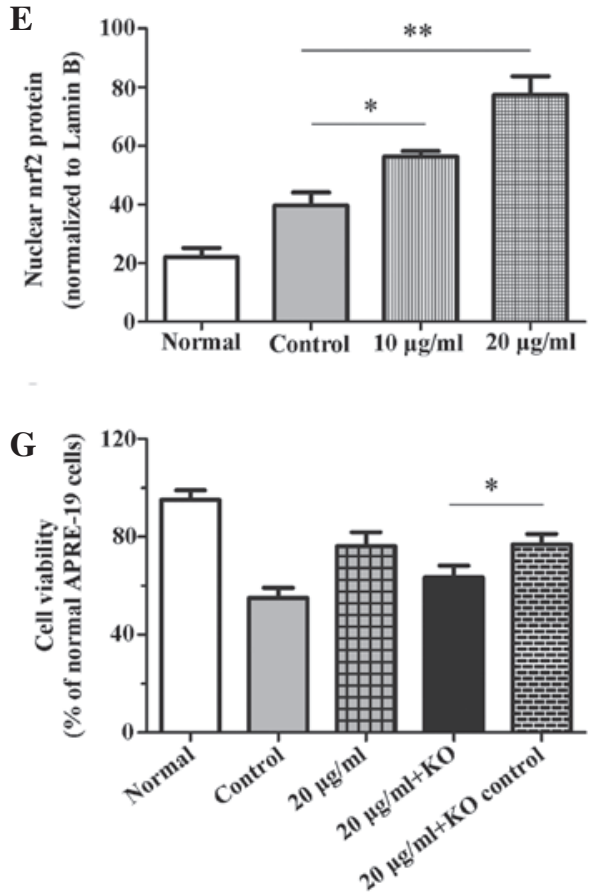

Figure 4. Nuclear factor erythroid 2-related factor 2 (Nrf2) is associated with allicin-mediated protection of retinal pigmented epithelial cells (RPEs) against hydrogen peroxide $\left(\mathrm{H}_{2} \mathrm{O}_{2}\right)$-induced injury. (A) Relative mRNA expression levels of $\mathrm{Nrf} 2$ were measured by reverse transcription-quantitative polymerase chain reaction. ARPE-19 cells exposed to $\mathrm{H}_{2} \mathrm{O}_{2}$ (control group) were denoted as $100 \%$. (B) Expression levels of cytosolic Nrf2 protein were determined by western blotting. (C) Band intensities were assessed and normalized to $\beta$-actin bands. (D) Expression levels of nuclear Nrf2 protein were determined by western blotting. (E) Band intensities were assessed and normalized to Lamin B bands. (F) Efficiency of Nrf2 knockdown was evaluated by western blotting. (G) Differences in cell viability were compared between the groups. Normal group, untreated cells; control group, cells treated with $250 \mu \mathrm{M} \mathrm{H}_{2} \mathrm{O}_{2} ; 20 \mu \mathrm{g} / \mathrm{ml}+$ knockout (KO) group, cells with small interfering RNA (siRNA)-mediated Nrf2 knockdown, treated with $20 \mu \mathrm{g} / \mathrm{ml}$ allicin and $250 \mu \mathrm{M} \mathrm{H}_{2} \mathrm{O}_{2} ; 20 \mu \mathrm{g} / \mathrm{ml}+\mathrm{KO}$ control group, cells transfected with non-target siRNA, treated with $20 \mu \mathrm{g} / \mathrm{ml}$ allicin and $250 \mu \mathrm{M} \mathrm{H}_{2} \mathrm{O}_{2}$. All experiments were performed in triplicate. Data are presented as the mean \pm standard error of the mean. ${ }^{*} \mathrm{P}<0.05$ and ${ }^{* *} \mathrm{P}<0.01$.

of Nrf2 were detected by western blotting. The cytosolic protein expression levels of $\mathrm{Nrf} 2$ were significantly increased following treatment with $20 \mu \mathrm{g} / \mathrm{ml}$ allicin ( $\mathrm{P}=0.008$; Fig. 4B and $\mathrm{C})$. Furthermore, the nuclear protein expression levels of Nrf2 were significantly elevated following treatment with allicin at both $10 \mu \mathrm{g} / \mathrm{ml}(\mathrm{P}=0.025)$ and $20 \mu \mathrm{g} / \mathrm{ml}(\mathrm{P}=0.008)$, as compared with the control cells (Fig. 4D and E). Therefore it was hypothesized that Nrf2 may be associated with the allicin-mediated protection of cells against $\mathrm{H}_{2} \mathrm{O}_{2}$-induced injury. To verify this hypothesis, differences in the viability of RPEs with or without Nrf2 knockdown were detected in the presence of $\mathrm{H}_{2} \mathrm{O}_{2}$ and allicin. As presented in Fig. 4F the Nrf2-siRNA effectively silenced Nrf2 gene expression in the RPEs. Nrf2 knockdown significantly attenuated the protection of allicin against $\mathrm{H}_{2} \mathrm{O}_{2}$-mediated 
loss of viability $(\mathrm{P}=0.032)$. However, Nrf2 knockdown did not completely suppress the protective effects of allicin (Control group 53.34 $\pm 5.01 \%$ vs. $20 \mu \mathrm{g} / \mathrm{ml}+$ knockdown group $63.06 \pm 7.85 \%$ ) (Fig. 4G). These data suggest that allicin may exert protective effects against $\mathrm{H}_{2} \mathrm{O}_{2}$-induced damage in RPEs not only via regulation of ROS-associated enzymes but also by elevating the activity of the antioxidant $\mathrm{Nrf} 2$.

\section{Discussion}

Allicin (2-propene-1-sulfinothioic acid S-2-propenyl ester) is a key component of garlic that is responsible for its pungent smell (28). The roles of allicin have been widely investigated with regards to antimicrobial, immune-modulatory and anticancer activity (9). Previous studies have particularly focused on the cardiovascular benefits of allicin, and its ability to elevate antioxidant status by lowering oxidative stress (29). Furthermore, allicin has been suggested as a potential therapy for the treatment of cognitive deficits in aging and Alzheimer's disease, due to its antioxidative activity (15). These previous findings have provided evidence suggesting that supplementation of allicin may improve antioxidant status and slow the progression of AMD; however, the effects of allicin on RPEs against oxidative stress, and the underlying mechanisms, have yet to be elucidated. Oxidative stress of RPEs has been considered a crucial role with regards to the pathophysiology of AMD (4). Therefore, recent studies have focused on strategies that protect RPEs from oxidative stress for the treatment of AMD. Exposure to $\mathrm{H}_{2} \mathrm{O}_{2}$ is often used as a classic model to convey the oxidative stress susceptibility and antioxidant activity of RPEs $(30,31)$. The present study determined the protective effects of allicin on RPEs exposed to $\mathrm{H}_{2} \mathrm{O}_{2}$. Notably, allicin was able to attenuate the reduced viability induced by $\mathrm{H}_{2} \mathrm{O}_{2}$. These results suggested that allicin may exert protective effects against oxidative stress-induced damage in RPEs. These data further our understanding of the protective effects of allicin against oxidative stress not only with regards to neuroprotection and cardioprotection $(14,15,29,32)$, but also vision protection.

Intracellular accumulation of ROS is associated with oxidative stress and RPE dysfunction $(33,34)$. Reductions in the levels of intracellular ROS are able to protect RPEs from oxidative stress $(33,35)$. The results of the present study demonstrated that allicin markedly reduced $\mathrm{H}_{2} \mathrm{O}_{2}$-induced intracellular ROS levels in RPEs. The ratio of GSH/GSSG is known to reflect the extent of oxidative stress in cells (21). The present study demonstrated that preincubation with allicin increased the GSH/GSSG ratio, thus suggesting that allicin may combat oxidative stress. In addition, the levels of MDA, a biomarker of oxidative stress, were measured. MDA levels indirectly reflect the severity of oxidative stress caused by free radicals (13). In the present study, allicin preincubation reduced the $\mathrm{H}_{2} \mathrm{O}_{2}$-induced levels of MDA in ARPE-19 cells. These data indicated that allicin may possess the ability to indirectly scavenge oxygen free radicals. Therefore allicin may decrease $\mathrm{H}_{2} \mathrm{O}_{2}$-induced oxidative stress in ARPE-19 cells by decreasing intracellular ROS levels and scavenging oxygen free radicals.

The present study also aimed to determine the mechanisms underlying the protective effects of allicin against oxidative stress in ARPE-19 cells. The present study demonstrated that allicin may reduce the levels of intracellular ROS in ARPE-19 cells exposed to $\mathrm{H}_{2} \mathrm{O}_{2}$. Therefore, the expression levels of NOX4, a key enzyme associated with ROS generation, were measured $(23,24)$. Notably, following treatment with allicin, the NOX4 protein and mRNA expression levels were attenuated. Furthermore, SOD, which is an enzyme capable of indirectly scavenging oxygen free radicals (16), was measured; allicin significantly elevated the levels of SOD. These results further supported the hypothesis that allicin may be able to indirectly scavenge oxygen free radicals in ARPE-19 cells exposed to oxidative stress. Chan et al (13) reported that allicin inhibited intracellular ROS production, rather than scavenging extracellular $\mathrm{H}_{2} \mathrm{O}_{2}$ or free radicals in $\mathrm{H} 9 \mathrm{C} 2$ cells. Conversely, allicin has been shown to exhibit the ability to indirectly scavenge oxygen free radicals in human umbilical vein endothelial cells (16), which is consistent with the findings of the present study. Therefore, the present study hypothesized that allicin may exert various biological abilities in order to protect against oxidative stress in various cell lines and tissues. Furthermore, NQO1 is an important enzyme, which has an essential antioxidant role (25). The protein expression levels of NQO1 were upregulated in $\mathrm{H}_{2} \mathrm{O}_{2}$-stimulated ARPE-19 cells following allicin pretreatment. These data indicated that protection of RPEs is dependent on the regulation of enzymes that reduce intracellular ROS production, scavenge free radicals and enhance antioxidant ability.

Nrf2 is a ubiquitous transcription factor, which has critical effects on maintenance of cellular homeostasis (36). It is well-known that Nrf2 mediates an antioxidant response pathway that promotes the primary cellular defense mechanism against oxidative stress induced by xenobiotic exposure and other factors $(36,37)$. The antioxidative effects of allicin are associated with the Nrf2 antioxidant signaling pathway in cardiovascular diseases, neurodegenerative diseases and cancer $(15,38,39)$. To further investigate the antioxidative effects of allicin on ARPE-19 cells exposed to $\mathrm{H}_{2} \mathrm{O}_{2}$, the expression levels of $\mathrm{Nrf} 2$ were detected. Nrf2 expression levels were significantly elevated following treatment with allicin. Furthermore, knockdown of Nrf2 significantly attenuated the protective effects of allicin against $\mathrm{H}_{2} \mathrm{O}_{2}$-mediated loss of viability. These results indicated that the Nrf2-mediated antioxidant response pathway is associated with the antioxidative effects of allicin on RPEs exposed to oxidative stress.

In conclusion, allicin exerted protective effects against oxidative stress-induced damage of RPEs via regulation of the ROS system, including reducing intracellular ROS production, scavenging free radicals, enhancing antioxidant ability, and stimulating the Nrf2-mediated antioxidant response pathway. These findings suggested that allicin may be considered a potential drug for the prevention and treatment of AMD.

\section{Acknowledgements}

The present study was supported by the Renmin Hospital of Wuhan University (grant no. RHWU-13-2012) and Inner Mongolia People's Hospital (grant no. 2012-16-02).

\section{References}

1. Wang ZY, Shen LJ, Tu L, Hu DN, Liu GY, Zhou ZL, Lin Y, Chen $\mathrm{LH}$ and $\mathrm{Qu} \mathrm{J}$ : Erythropoietin protects retinal pigment epithelial cells from oxidative damage. Free Radic Biol Med 46: 1032-1041, 2009. 
2. Winkler BS, Boulton ME, Gottsch JD and Sternberg P: Oxidative damage and age-related macular degeneration. Mol Vis 5: 32, 1999.

3. Congdon NG, Friedman DS and Lietman T: Important causes of visual impairment in the world today. JAMA 290: 2057-2060, 2003.

4. Beatty S, Koh H, Phil M, Henson D and Boulton M: The role of oxidative stress in the pathogenesis of age-related macular degeneration. Surv Ophthalmol 45: 115-134, 2000

5. Dentchev T, Hahn P and Dunaief JL: Strong labeling for iron and the iron-handling proteins ferritin and ferroportin in the photoreceptor layer in age-related macular degeneration. Arch Ophthalmol 123: 1745-1746, 2005.

6. Kietzmann T: Intracellular redox compartments: Mechanisms and significances. Antioxid Redox Signal 13: 395-398, 2010.

7. Rishton GM: Natural products as a robust source of new drugs and drug leads: Past successes and present day issues. Am J Cardiol 101: 43D-49D, 2008.

8. Chan SW:Panax ginseng, Rhodiolarosea and Schisandrachinensis. Int J Food Sci Nutr 63 (Suppl 1): 75-81, 2012.

9. Borlinghaus J, Albrecht F, Gruhlke MC, Nwachukwu ID and Slusarenko AJ: Allicin: Chemistry and biological properties. Molecules 19: 12591-12618, 2014.

10. Kita T, Kume N, Minami M, Hayashida K, Murayama T, Sano H Moriwaki H, Kataoka H, Nishi E, Horiuchi H, et al: Role of oxidized LDL in atherosclerosis. Ann NY Acad Sci 947: 199-205; discussion 205-206, 2001

11. Arzanlou M, Bohlooli S, Jannati E and Mirzanejad-Asl $\mathrm{H}$ : Allicin from garlic neutralizes the hemolytic activity of intra- and extra-cellular pneumolysin O in vitro. Toxicon 57: 540-545, 2011.

12. IzigovN,FarzamNandSavionN:S-allylmercapto-N-acetylcysteine up-regulates cellular glutathione and protects vascular endothelial cells from oxidative stress. Free Radic Biol Med 50: 1131-1139, 2011.

13. Chan JY, Tsui HT, Chung IY, Chan RY, Kwan YW and Chan SW: Allicin protects rat cardiomyoblasts (H9c2 cells) from hydrogen peroxide-induced oxidative injury through inhibiting the generation of intracellular reactive oxygen species. Int J Food Sci Nutr 65: 868-873, 2014

14. Abramovitz D, Gavri S, Harats D, Levkovitz H, Mirelman D, Miron T, Eilat-Adar S, Rabinkov A, Wilchek M, Eldar M and Vered Z: Allicin-induced decrease in formation of fatty streaks (atherosclerosis) in mice fed a cholesterol-rich diet. Coron Artery Dis 10: 515-519, 1999

15. Li XH, Li CY, Lu JM, Tian RB and Wei J: Allicin ameliorates cognitive deficits ageing-induced learning and memory deficits through enhancing of Nrf2 antioxidant signaling pathways. Neurosci Lett 514: 46-50, 2012.

16. Chen S, Tang Y, Qian Y, Chen R, Zhang L, Wo L and Chai H: Allicin prevents $\mathrm{H}_{2} \mathrm{O}_{2}$-induced apoptosis of HUVECs by inhibiting an oxidative stress pathway. BMC Complement Altern Med 14: 321, 2014.

17. Schmittgen TD and Livak KJ: Analyzing real-time PCR data by the comparative C(T) method. Nat Protoc 3: 1101-1108, 2008.

18. Lee SH, Kim JK and Jang HD: Genistein inhibits osteoclastic differentiation of RAW 264.7 cells via regulation of ROS production and scavenging. Int J Mol Sci 15: 10605-10621, 2014.

19. Koskela A, Reinisalo M, Hyttinen JM, Kaarniranta K and Karjalainen RO: Pinosylvin-mediated protection against oxidative stress in human retinal pigment epithelial cells. Mol Vis 20: 760-769, 2014

20. Wasserman WW and Fahl WE: Functional antioxidant responsive elements. Proc Natl Acad Sci USA 94: 5361-5366, 1997.
21. Lin M, Li L, Zhang Y, Zheng L, Xu M, Rong R and Zhu T: Baicalin ameliorates $\mathrm{H}_{2} \mathrm{O}_{2}$ induced cytotoxicity in HK-2 cells through the inhibition of ER stress and the activation of Nrf2 signaling. Int J Mol Sci 15: 12507-12522, 2014.

22. Ho E, Karimi Galougahi K, Liu CC, Bhindi R and Figtree GA Biological markers of oxidative stress: Applications to cardiovascular research and practice. Redox Biol 1: 483-491, 2013.

23. Bedard K and Krause KH: The NOX family of ROS-generating NADPH oxidases: Physiology and pathophysiology. Physiol Rev 87: 245-313, 2007.

24. Block K, Gorin Y and Abboud HE: Subcellular localization of Nox4 and regulation in diabetes. Proc Natl Acad Sci USA 106 14385-14390, 2009.

25. Zhu C, Pan F, Ge L, Zhou J, Chen L, Zhou T, Zong R, Xiao X, Dong N, Yang M, et al: SERPINA3K plays antioxidant roles in cultured pterygial epithelial cells through regulating ROS system. PLoS One 9: e108859, 2014.

26. Schelonka LP, Siegel D, Wilson MW, Meininger A and Ross D: Immunohistochemical localization of NQO1 in epithelial dysplasia and neoplasia and in donor eyes. Invest Ophthalmol Vis Sci 41: 1617-1622, 2000.

27. Nguyen T, Nioi P and Pickett CB: The Nrf2-antioxidant response element signaling pathway and its activation by oxidative stress. J Biol Chem 284: 13291-13295, 2009.

28. Chu YL, Ho CT, Chung JG, Rajasekaran R and Sheen LY: Allicin induces p53-mediated autophagy in Hep G2 human liver cancer cells. J Agric Food Chem 60: 8363-8371, 2012.

29. Chan JY, Yuen AC, Chan RY and Chan SW: A review of the cardiovascular benefits and antioxidant properties of allicin. Phytother Res 27: 637-646, 2013.

30. Geiger RC, Waters CM, Kamp DW and Glucksberg MR: KGF prevents oxygen-mediated damage in ARPE-19 cells. Invest Ophthalmol Vis Sci 46: 3435-3442, 2005.

31. Zareba M, Raciti MW, Henry MM, Sarna T and Burke JM: Oxidative stress in ARPE-19 cultures: Do melanosomes confer cytoprotection? Free Radic Biol Med 40: 87-100, 2006.

32. Zhu JW, Chen T, Guan J, Liu WB and Liu J: Neuroprotective effects of allicin on spinal cord ischemia-reperfusion injury via improvement of mitochondrial function in rabbits. Neurochem Int 61: 640-648, 2012

33. Yamada Y, Tian J, Yang Y, Cutler RG, Wu T, Telljohann RS, Mattson MP and Handa JT: Oxidized low density lipoproteins induce a pathologic response by retinal pigmented epithelial cells. J Neurochem 105: 1187-1197, 2008.

34. Witmer AN, Vrensen GF, Van Noorden CJ and Schlingemann RO: Vascular endothelial growth factors and angiogenesis in eye disease. Prog Retin Eye Res 22: 1-29, 2003.

35. Cakir Y and Ballinger SW: Reactive species-mediated regulation of cell signaling and the cell cycle: The role of MAPK. Antioxid Redox Signal 7: 726-740, 2005.

36. Ma Q: Role of nrf2 in oxidative stress and toxicity. Annu Rev Pharmacol Toxicol 53: 401-426, 2013.

37. Ma Q and He X: Molecular basis of electrophilic and oxidative defense: Promises and perils of Nrf2. Pharmacol Rev 64: 1055-1081, 2012.

38. Cardozo LF, Pedruzzi LM, Stenvinkel P, Stockler-Pinto MB, Daleprane JB, Leite M Jr and Mafra D: Nutritional strategies to modulate inflammation and oxidative stress pathways via activation of the master antioxidant switch Nrf2. Biochimie 95 $1525-1533,2013$.

39. Bat-Chen W, Golan T, Peri I, Ludmer Z and Schwartz B: Allicin purified from fresh garlic cloves induces apoptosis in colon cancer cells via Nrf2. Nutr Cancer 62: 947-957, 2010 . 